\title{
Hallucinogen-Induced UP States in the Brain Slice of Rat Prefrontal Cortex: Role of Glutamate Spillover and NR2B-NMDA Receptors
}

\author{
Evelyn K Lambe*,' and George K Aghajanian ${ }^{1,2}$ \\ 'Department of Psychiatry, Yale School of Medicine, New Haven, CT, USA; ${ }^{2}$ Department of Pharmacology, Yale School of Medicine, \\ New Haven, CT, USA
}

Psychedelic hallucinogens (eg LSD or DOI) induce disturbances of mood, perception, and cognition through stimulation of serotonin $5-\mathrm{HT}_{2 \mathrm{~A}}$ receptors. While these drugs are not proconvulsant, they have been shown by microdialysis to increase extracellular glutamate in the prefrontal cortex. Electrophysiological studies in the rat prefrontal slice have shown that both LSD and DOI enhance a prolonged, late wave of glutamate release onto layer $\vee$ pyramidal neurons after an electrical stimulus. Here, we hypothesize that the network activity underlying this UP state involves glutamate spillover from excitatory synapses. To test this hypothesis, we raised the viscosity of the extracellular solution by adding the inert macromolecule dextran $(\sim 1 \mathrm{mM})$ that is known to retard glutamate overflow into the extrasynaptic space. Dextran suppressed the UP state or late excitatory postsynaptic current (EPSC), but neither the fast EPSC, the traditional polysynaptic EPSC, nor a synaptic form of 5- $\mathrm{HT}_{2 \mathrm{~A}}$-mediated transmission (serotonin-induced spontaneous EPSCs). Consistent with the previous work showing that extrasynaptic glutamate transmission in adult depends on NR2B-containing NMDA receptors, we found that NR2B-selective antagonists, ifenprodil and Ro25-698I, also suppressed the late EPSCs. The effect of psychedelic hallucinogens on UP states could be partially mimicked by inhibiting glutamate uptake but only after blocking inhibitory group II metabotropic glutamate receptors. This difference suggests that hallucinogens increase glutamate spillover in a phasic manner unlike glutamate uptake inhibitors. Increases in glutamate spillover have been suggested to recruit synapses not directly in the pathway activated by the electrical stimulus. Such recruitment could account for certain cognitive, affective, and sensory perturbations generated by psychedelic hallucinogens. Neuropsychopharmacology (2006) 31, 1682- 1689. doi:I 0.1038/sj.npp. 1300944; published online 2 November 2005

Keywords: 5- $\mathrm{HT}_{2 \mathrm{~A}}$ receptors; extrasynaptic; electrophysiology; glutamate; NMDA receptors; UP states; prefrontal cortex

\section{INTRODUCTION}

Psychedelic hallucinogens alter many aspects of cortical function through their activation of $5-\mathrm{HT}_{2 \mathrm{~A}}$ receptors (for a review, see Nichols, 2004). Imaging studies in humans have shown that both indolamine and phenethlylamine hallucinogens increase the prefrontal cortex activation (Vollenweider et al, 1997; Gouzoulis-Mayfrank et al, 1999). Consistent with such activation, microdialysis studies in rats have shown that psychedelic hallucinogens increase extracellular levels of the excitatory amino acid, glutamate (Scruggs et al, 2003; Muschamp et al, 2004). Interestingly, psychedelic hallucinogens are not proconvulsant; in fact,

*Correspondence: Dr EK Lambe, Department of Psychiatry, Yale School of Medicine, Ribicoff Room 307, CMHC, 34 Park Street, New Haven, CT 06508, USA. Tel: + I 203974 777I; Fax:+ I 203974 7897; E-mail: evelyn.lambe@yale.edu

Received 18 May 2005; revised 26 August 2005; accepted 15 September 2005

Online publication: 19 September 2005 at http://www.acnp.org/ citations/Npp091905050333/default.pdf numerous EEG studies show that LSD promotes the desynchronized brain waves of active waking rather than epileptiform activity (reviewed in Rodin and Luby, 1966). Electrophysiological studies in rats show that indolamine (eg lysergic acid diethylamine; LSD) and phenethlylamine (eg 1-(2,5-dimethoxy-4-iodophenyl-2-aminopropane (DOI)) hallucinogens enhance a delayed form of glutamate release through their partial agonist actions at $5-\mathrm{HT}_{2 \mathrm{~A}}$ receptors (Aghajanian and Marek, 1999). This late wave of glutamate release depends on activation of NMDA receptors (Stutzmann et al, 2001) and resembles the UP states resulting from sustained activity in balanced excitatory and inhibitory recurrent networks described recently (Shu et al, 2003; Hasenstaub et al, 2005). In the adult rat prefrontal cortex, under typical submerged slice conditions, this phenomenon can be observed only infrequently in the absence of psychedelic hallucinogen (eg when a pathway is stimulated after a long quiescent period). The application of a low concentration of a psychedelic hallucinogen to the brain slice allows this late wave or UP state to occur much more frequently. The ability of psychedelic hallucinogens to promote or 
exaggerate UP states in vivo would have profound repercussions for perception, mood, and cognition.

A growing body of literature suggests that activation of high-affinity extrasynaptic NMDA receptors by glutamatergic spillover may play a significant role in the brain function (Kullmann et al, 1996; Barbour and Hausser, 1997; Rusakov and Kullmann, 1998; Scimemi et al, 2004; Lozovaya et al, 2004). According to this view, the activation of any one synapse would not only activate its immediate postsynaptic partner, but may also - depending on conditions - be able to activate high-affinity NMDA receptors at adjacent spines or presynaptic terminals. While the diffusion of glutamate appears highly regulated by glial and neuronal uptake mechanisms (reviewed in Huang and Bergles, 2004), dendritic spines in the cerebral cortex are unusual in their relative lack of glial cover (Spacek, 1985). Since spillover would preferentially activate high-affinity NMDA receptors, it has been suggested that under normal physiological conditions it would not interfere with fast point-to-point transmission but instead may enhance responsiveness of the network (Shu et al, 2003; Scimemi et al, 2004). In fact, there are aspects of the subjective effects of psychedelic hallucinogens that appear consistent with enhancing interactions between synapses that would normally not experience 'cross talk,' - that is, altered sensory perception, increased emotional lability, and disturbed cognitive processing.

In this study, we investigate whether the psychedelic hallucinogens LSD and DOI enhance extrasynaptic transmission of glutamate in the brain slice of prefrontal cortex. First, we retard the diffusion of glutamate beyond the synapse by changing the viscosity of the extracellular space using dextran, a macromolecule that has often been employed to suppress spillover (Min et al, 1998; Perrais and Ropert, 2000; Nielsen et al, 2004; Piet et al, 2004; Savtchenko and Rusakov, 2005). Then, we assess the subtypes of NMDA receptors that are involved in the delayed wave of glutamate enhanced by psychedelic hallucinogens. Finally, we test whether blocking glutamate uptake is able to mimic LSD or DOI.

\section{METHODS}

Coronal slices $(400 \mu \mathrm{m}$ thick) of the medial prefrontal cortex were prepared from adolescent/young adult Sprague-Dawley rats (35-60 days old), in accordance with protocols approved by the Yale University Animal Care and Use Committee. Slices were cut in chilled $\left(\sim 4^{\circ}\right)$, oxygenated ACSF in which $254 \mathrm{mM}$ sucrose was substituted for $\mathrm{NaCl}$, then placed in a modified perfusion chamber (Warner Instruments, Hamden, CT) mounted on the stage of an Olympus BX50WI microscope (Olympus; Melville, NY). Regular ACSF (128 mM NaCl, $3 \mathrm{mM} \mathrm{KCl,} 1.25 \mathrm{mM} \mathrm{NaH}_{2} \mathrm{PO}_{4}$, $10 \mathrm{mM}$ D-glucose, $26 \mathrm{mM} \mathrm{NaHCO}_{3}, 2 \mathrm{mM} \mathrm{CaCl}_{2}$ and $2 \mathrm{mM}$ $\mathrm{MgSO}_{4} ; \mathrm{pH} 7.35$ ) was bubbled with $95 \%$ oxygen and $5 \%$ carbon dioxide, warmed, and flowed over slice at $30-34^{\circ}$ Celsius (3-4 $\mathrm{ml} / \mathrm{min})$.

Platinum-irridium bipolar stimulating electrodes with $3 \mu \mathrm{m}$ tips (FHC, Bowdoinham, ME) were placed midlayer in the medial prefrontal cortex and controlled via a Pulsemaster A300 interval generator (WPI, Sarasota, FL) and a stimulus isolation unit (Axon Instruments, Union City, CA). Whole-cell patch electrodes (4-6 M) contained $120 \mathrm{mM}$ potassium gluconate, $5 \mathrm{mM} \mathrm{KCl,} 2 \mathrm{mM} \mathrm{MgCl}, 4 \mathrm{mM} \mathrm{K}_{2^{-}}$ ATP, $0.4 \mathrm{mM} \mathrm{Na}_{2}$-GTP, $10 \mathrm{mM} \mathrm{Na}$-phosphocreatine, and $10 \mathrm{mM}$ HEPES (adjusted to $\mathrm{pH} 7.33$ with $\mathrm{KOH}$ ). Neurons were patched under visual control using IR-DIC microscopy. Currents were recorded using continuous single electrode voltage clamp mode with an Axoclamp 2A, lowpass filtered at $3 \mathrm{kHz}$, amplified $100 \times$ through Cyberamp and digitized at $15 \mathrm{kHz}$, and acquired using pClamp/ Digidata 1200 (Axon Instruments). The neurons were voltage-clamped near their resting potential. The tips of the stimulating electrodes were located either in layer II/III or layer $\mathrm{V}(50-500 \mu \mathrm{m}$ dorsal or ventral) from the patched neuron. The stimulating currents employed were $0.2 \mathrm{~ms}$ in duration and ranged from 5 to $25 \mu \mathrm{A}$ in amplitude. During the baseline period in each experiment, stimuli were adjusted to produce a distinct fast EPSC but kept below the level that recruited late outward currents.

Fast and late EPSC areas ( $\left.\mathrm{pA}^{\star} \mathrm{ms}\right)$ were measured using Axograph software. The measurement was performed by determining the absolute area under the curve from the point of return to baseline after the fast EPSC (or deviation from smooth decay phase in the case of a late EPSC that emerged without a return to baseline) to the point of return to baseline (or end of the trace) after the late EPSC. Analysis of spontaneous EPSCs from each $10 \mathrm{~s}$ block of sweeps was performed using MiniAnalysis software (Synaptosoft Inc., Decatur, GA), as described previously (Lambe and Aghajanian, 2003). Group statistical significance was assessed using paired $t$-tests. Averages were expressed as mean \pm standard error (SE).

Drugs were applied in the fast-flowing bath. Drugs were obtained from Sigma (St Louis, MO). The dextran solution was prepared according to previously established methods (Min et al, 1998; Nielsen et al, 2004). Dextran ( $\sim 40 \mathrm{kDa})$ was added to standard ACSF in a concentration of $5 \%$ and rendered iso-osmotic by diluting the solution with water $(\sim 6 \%)$. Flow rate and temperature were kept constant during application of dextran.

\section{RESULTS}

\section{Effects of a Hallucinogen on Electrophysiological Properties of Layer V Neurons}

DOI $(3 \mu \mathrm{M}, 15 \mathrm{~min}$; 5-100 min washout) had little or no effect on membrane and spike properties of layer $\mathrm{V}$ pyramidal neurons, consistent with previous slice work in older animals (Zhang, 2003; Beique et al, 2004). All neurons were tested within 3 min of achieving whole-cell configuration, $N=9$ neurons before DOI, resting potential: $-69.9 \pm 1.5 \mathrm{mV}$, spike amplitude: $90.0 \pm 2.5 \mathrm{mV}$; input resistance: $86.1 \pm 9.5 \mathrm{M} \Omega ; N=10$ cells after DOI, resting potential: $-69.1 \pm 0.9 \mathrm{mV}$; spike amplitude $90.7 \pm 2.8 \mathrm{mV}$; input resistance: $90.0 \pm 13.6 \mathrm{M} \Omega$. There was a nonsignificant trend for neurons to be more excitable after DOI (before DOI, $N=9$ neurons; $4.0 \pm 0.4$ spikes with injection of $0.2 \mathrm{nA}$ depolarizing current; after DOI, $4.3 \pm 0.3$ spikes with the same current $N=10$ neurons). In neurons that were followed before, during, and after DOI application (see example in Figure 1), two of five showed an increase in 
excitability, as measured by an increase in spikes in response to a depolarizing current, and three of five showed a small increase in spontaneous excitatory postsynaptic potentials as previously reported (Marek and Aghajanian, 1999).

\section{Psychedelic Hallucinogens Enhance Extrasynaptic Transmission}

As described previously (Aghajanian and Marek, 1999; Stutzmann et al, 2001), slow rates $(0.1 \mathrm{~Hz})$ of electrical stimulation in either layer II/III or layer V of the medial prefrontal cortex induces fast excitatory postsynaptic currents (fast EPSCs) in pyramidal neurons in layer $\mathrm{V}$. Bath application of either DOI $(3 \mu \mathrm{M}, 15 \mathrm{~min})$ of LSD $(10 \mathrm{nM}, 10 \mathrm{~min})$ elicits a late wave of glutamate release (late EPSC) after each fast evoked response $(0.1 \mathrm{~Hz})$, as shown in Figure 2. These hallucinogen-enhanced late EPSCs can be

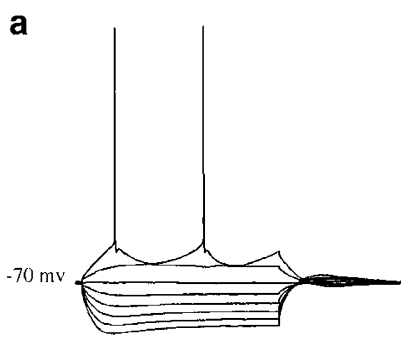

Baseline

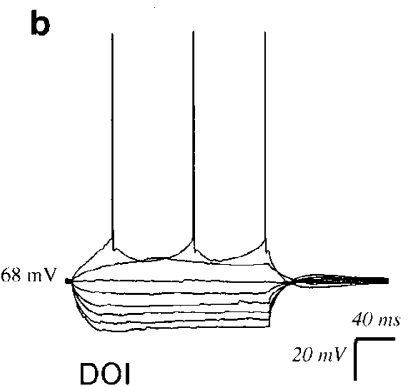

$\mathrm{DOI}$ extremely prolonged, lasting up to $2 \mathrm{~s}$ in some neurons. The effect becomes refractory at more frequent rates of stimulation and at $1 \mathrm{~Hz}$ stimulation is suppressed completely, although the fast EPSC does not appear to have changed. The effect of LSD and DOI is very slow to wash out, lasting more than $2 \mathrm{~h}$ without reapplication of drug. Stimulation in either layer II/III or V was effective at eliciting late EPSCs in the presence of DOI in $100 \%$ of the traces at $0.1 \mathrm{~Hz}$ under the recording conditions used in this study (this effect is temperature dependent and occurs less frequently at temperatures below $30^{\circ} \mathrm{C}$ ). Previous work has shown that the hallucinogen-enhanced late EPSC (but not the fast EPSC) can be suppressed by the selective $5-\mathrm{HT}_{2 \mathrm{~A}}$ antagonist MDL100907 (Aghajanian and Marek, 1999) and depends on NMDA activation (Stutzmann et al, 2001). This NMDA activation appears to be in the network since the late EPSC is mediated postsynaptically by AMPA receptors in cells recorded at hyperpolarized resting potentials and, like the fast EPSC, can be blocked with AMPA/kainate antagonists (eg LY293558 or CNQX) (Aghajanian and Marek, 1999). Figure 2 shows that wash-in of $5 \%$ dextran $(\sim 1 \mathrm{mM})$ dramatically attenuated the late EPSCs without significantly changing the fast EPSC. Note that early components of the late EPSC, which are in the range of conventional polysynaptic responses, are less affected by dextran (see arrows in Figure 2). The late EPSCs remained substantially suppressed for at least 5 min into the washout of dextran and recovered slowly over the next 5-10 min. The mean data for five neurons with LSD and six neurons with DOI are summarized in Figure 2c. The fast EPSC provided an internal control to test whether dextran interfered with monosynaptic transmission. In addition, we tested a monosynaptic form of $5-\mathrm{HT}_{2 \mathrm{~A}}$-mediated neurotransmission, the induction of spontaneous EPSCs, - to ensure that dextran was not interfering with $5-\mathrm{HT}_{2 \mathrm{~A}}$ receptors or transduction pathways. As shown in Figure 3, dextran did not suppress either the frequency or the amplitude of ingure I Membrane and spiking properties of a typical neuron record in this study in response to depolarizing and hyperpolarizing current pulses. Current clamp traces (0.I nA steps) from a layer $\vee$ pyramidal recorded (a) before and (b) after application of DOI ( $3 \mu \mathrm{M}, 15 \mathrm{~min})$. Note slight increase in spontaneous excitatory postsynaptic potentials following DOI.

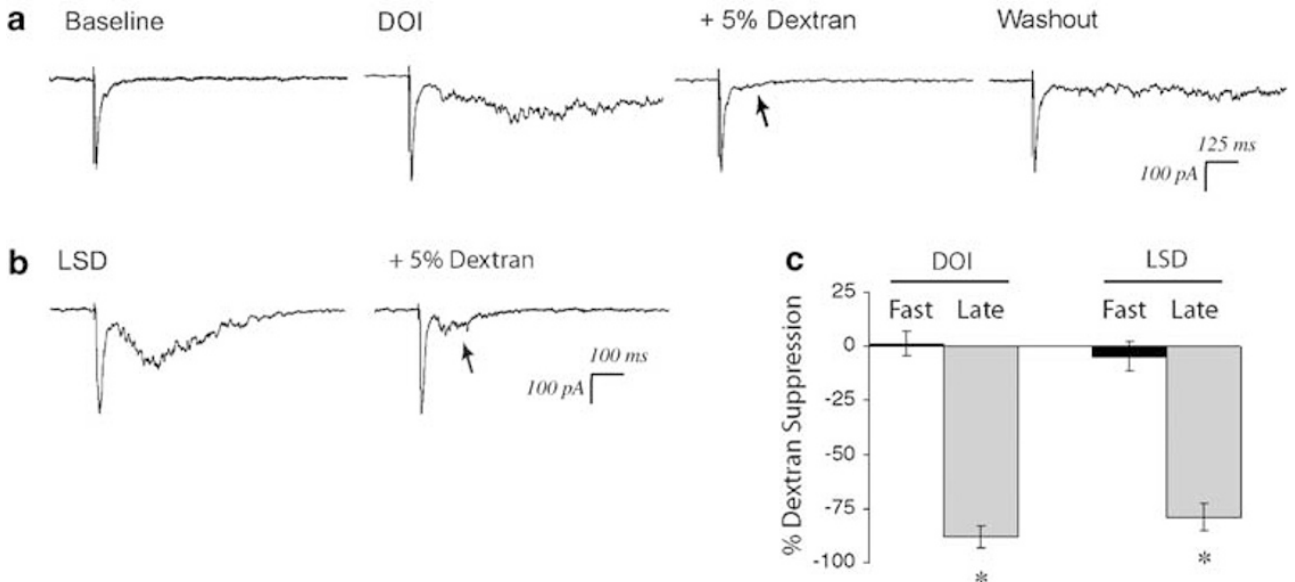

Figure 2 Increasing the viscosity of the extracellular fluid with 5\% dextran suppresses the late excitatory postsynaptic currents (late EPSCs) enhanced by psychedelic hallucinogens but does not suppress the electrically evoked fast EPSC. (a) EPSCs evoked electrically $(10 \mu \mathrm{A}$ stimuli given at $0.1 \mathrm{~Hz}$, each trace is the average of 10 sweeps; $V_{H}=-75 \mathrm{mV}$ ) under baseline conditions, after DOI ( $3 \mu \mathrm{M} ; 15 \mathrm{~min}$ ), with $5 \%$ dextran ( 4 min), and after partial washout of dextran (8 min). Note the absence of a discernable late EPSC prior to DOI application. (b) EPSCs evoked electrically $(\mathrm{I} 0 \mu \mathrm{A}$ stimuli given at $0 . \mathrm{I} \mathrm{Hz}$, each trace is the average of 10 sweeps; $V_{H}=-75 \mathrm{mV}$ ) after LSD ( $10 \mathrm{nM}, 10 \mathrm{~min}$ ) with $5 \%$ dextran (4 min) $(10 \mu \mathrm{A}$ stimuli given at $0.1 \mathrm{~Hz}$, each trace is the average of 10 sweeps; $V_{H}=-75 \mathrm{mV}$ ). Note that an early phase of the late EPSC following DOI and LSD is relatively resistant to dextran (arrows). (c) Bar graph showing percent suppression (mean \pm SE) by dextran of fast EPSC and late EPSC areas after DOI $(n=6$ cells; $* P<0.0$ I) or after LSD $(n=5$ cells; *P $<0.0$ I).

Neuropsychopharmacology 
a
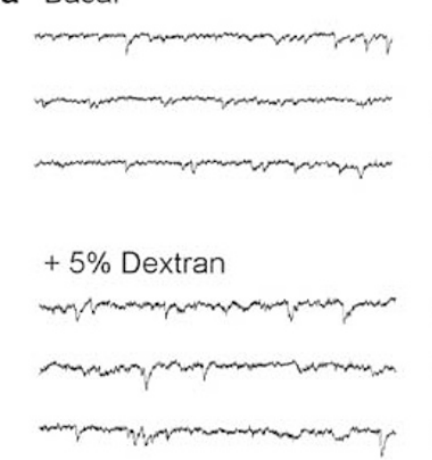

b

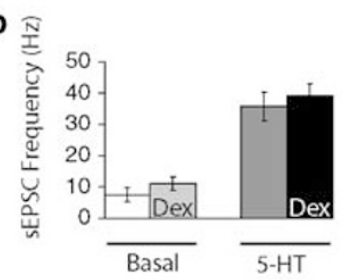

c Baseline

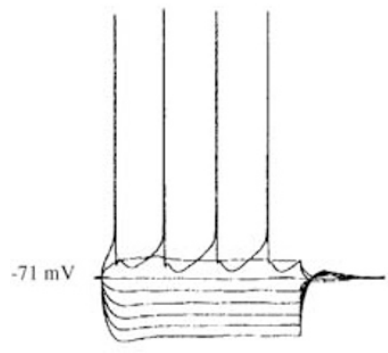

5-HT

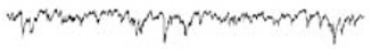

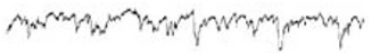

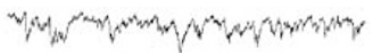
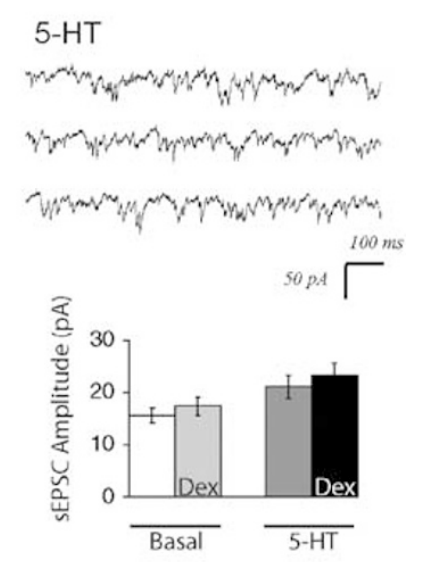

$+5 \%$ Dextran

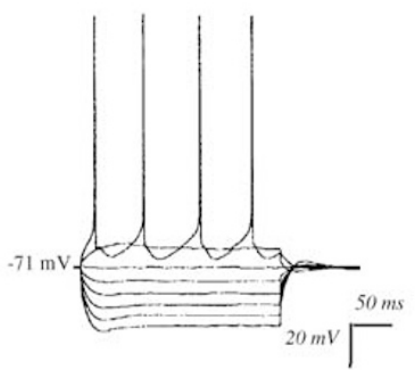

Figure 3 Synaptic 5- $\mathrm{HT}_{2 \mathrm{~A}}$-elicited spontaneous EPSCs are not suppressed by $5 \%$ dextran. (a) Example sweeps (I s) in voltage clamp $\left(V_{H}=-75 \mathrm{mV}\right)$ showing basal sEPSCs and those induced by $5-\mathrm{HT}(20 \mu \mathrm{M}$, I min). Spontaneous EPSCs in the same neuron are shown below after $10 \mathrm{~min}$ bath application of $5 \%$ dextran and with co-application of $5 \%$ dextran and 5-HT (20 $\mu \mathrm{M}$, I min). (b) Bar graphs show mean frequency and amplitude of basal and serotonin $5-\mathrm{HT}_{2 \mathrm{~A}}$-elicited spontaneous EPSCs before and during application of $5 \%$ dextran $(n=5)$. There were no significant effects of dextran. (c) Current clamp traces (0.I nA steps) from a layer $\vee$ pyramidal recorded before and during application of $5 \%$ dextran (5 min).

serotonin-induced spontaneous EPSCs. The mean data for five neurons are summarized in Figure 3b. In fact, there was a nonsignificant trend toward an increase in both basal and 5-HT-induced sEPSCs. Finally, as illustrated in Figure 3c, the excitability and membrane properties of the neurons were not significantly changed in the presence of $5 \%$ dextran: spike amplitude (basal: $88.8 \pm 4.1 \mathrm{mV}$; dextran: $87.8 \pm 5.5 \mathrm{mV}$ ), input resistance (basal: $82.6 \pm 9.2 \mathrm{M} \Omega$; dextran: $83.0 \pm 8.7 \mathrm{M} \Omega$ ), and membrane time constant measurement or tau (basal: $0.39 \pm 0.03$; dextran $0.41 \pm 0.03$ ). The selective suppression of the late EPSCs or UP states by dextran suggests that the late wave of glutamate release enhanced by psychedelic hallucinogens stimulates extrasynaptic rather than synaptic glutamate receptors.

Since recent studies in the adult rat have suggested that extrasynaptic glutamate transmission is mediated dispro-

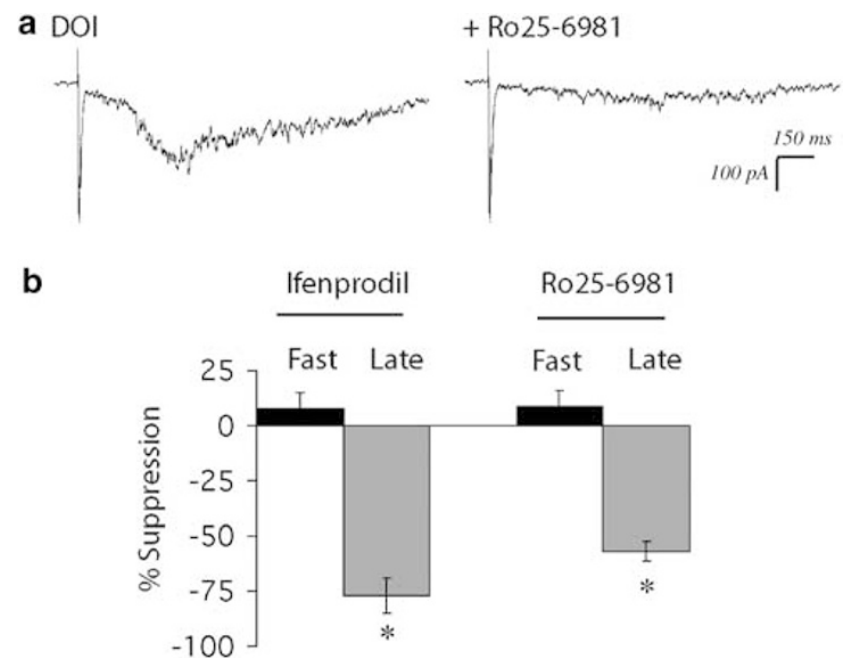

Figure 4 Selective antagonists for NMDA receptors that contain the NR2B subunit suppress the DOl-enhanced late EPSC but not the fast EPSC. (a) Averaged traces ( 10 sweeps) showing fast and late EPSCs after DOI ( 15 min; $3 \mu \mathrm{M}$ ) before and after application of Ro25-698I (500 nM, 10 min). (b) Bar graph showing percent suppression (mean \pm SE) of fast and late EPSC areas by ifenprodil $(3 \mu \mathrm{M} ; n=5 ; *<<0.01)$ and Ro25-698I $(500 \mathrm{nM} ; n=5 ; * P<0.05)$.

portionately by NMDA receptors that contain the NR2B subunit (Lozovaya et al, 2004; Scimemi et al, 2004), we assessed the ability of the selective NR2B antagonists Ro256981 (Fischer et al, 1997) and ifenprodil (Williams, 1993) to suppress DOI-enhanced late EPSCs. As shown in Figure 4, the late EPSC was markedly suppressed by either Ro25-6981 ( $500 \mathrm{nM}, 10 \mathrm{~min})$ or ifenprodil $(3 \mu \mathrm{M}, 10 \mathrm{~min})$. By contrast, neither Ro25-6981 nor ifenprodil had any significant effect on the fast EPSC.

\section{Effects of Inhibiting Glutamate Uptake}

Since glutamate uptake by transporters is known to be a major limiting factor on spillover under normal conditions in brain slice (Diamond, 2001; Huang and Bergles, 2004), their blockade is known to increase extracellular glutamate (Melendez et al, 2005), and $\mathrm{G}_{\mathrm{q}}$-coupled mechanisms can decrease surface expression of glutamate transporters (Kalandadze et al, 2002), we tested whether blocking glutamate uptake with a relatively low concentration of TBOA could enhance the occurrence of late EPSCs similarly to psychedelic hallucinogens. Figure 5 shows that TBOA (30 $\mu \mathrm{M}, 3-5 \mathrm{~min})$ only minimally enhanced late EPSCs. Since recent work has shown that the increase in ambient glutamate with TBOA additionally activates inhibitory group II metabotropic glutamate (mGlu2/3) receptors (Melendez et al, 2005), we hypothesized that an antagonist of inhibitory metabotropic glutamate receptors may allow TBOA to mimic the effects of psychedelic hallucinogens. In Figure 5, we illustrate that emergence of late EPSCs in the presence of TBOA depends critically on blockade of mGlu2/3 receptors. By contrast, the late EPSCs enhanced by DOI are not significantly increased by application of LY341495 (300 nM-1 $\mu \mathrm{M} ; 5 \pm 4 \%$ increase, $N=4$ ), compared to the effect of LY341495 on TBOA (300 nM; $350 \pm 26 \%$ increase; $N=5$ ). These results suggest that the timing of 
a

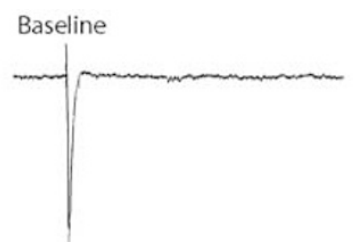

LY341495

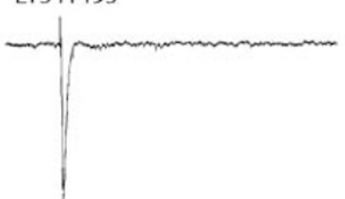

b

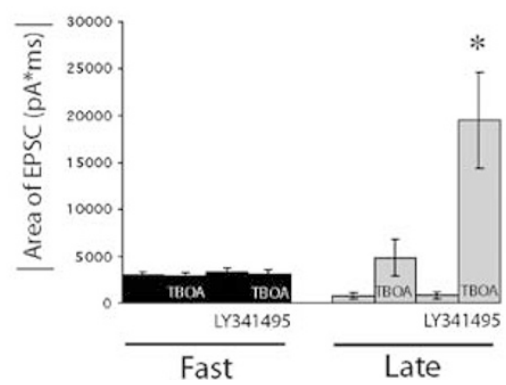

Figure 5 Blocking glutamate uptake with TBOA only partially enhances the late EPSC. In order to mimic the effect of psychedelic hallucinogens, it is necessary to concurrently block inhibitory group II metabotropic glutamate (mGlu2/3) receptors. (a) Averaged traces (10 sweeps) before and after application of TBOA ( $30 \mu \mathrm{M} ; 5 \mathrm{~min}$ ), followed by application of the $\mathrm{mGlu} 2 / 3$ receptor antagonist LY34I495 (300 nM, $10 \mathrm{~min})$. Prominent late EPSCs will only emerge after preapplication of LY34I495 during $0.1 \mathrm{~Hz}$ electrical stimulation in the presence of TBOA (30 $\mu \mathrm{M} ; 5 \mathrm{~min})$. (b) Bar graph showing the absolute area of fast and late EPSCs (mean \pm SE) before and during TBOA (30 $\mu$ M; $5 \mathrm{~min})$, application of LY34I 495 (300 nM, $10 \mathrm{~min})$, and repeat application of TBOA $(30 \mu \mathrm{M} ; 5 \mathrm{~min})(n=5$; $* P<0.05)$.

the glutamate spillover enhanced by psychedelic hallucinogens is different from the increase in ambient levels of glutamate with TBOA. In microdialysis studies, however, time-averaging means that the phasic increases in glutamate spillover with DOI would appear similar to the tonic increases with glutamate uptake inhibition.

\section{DISCUSSION}

The late EPSCs or UP states enhanced by psychedelic hallucinogens behave in a manner that is consistent with the involvement of glutamate spillover. These late EPSCs are selectively suppressed by increasing the viscosity of the extracellular space, a manipulation known to retard extrasynaptic transmission (Min et al, 1998; Perrais and Ropert, 2000; Nielsen et al, 2004). They also depend on NR2B-containing NMDA receptors, a population thought to be mainly extrasynaptic in the adolescent and adult rat (Stocca and Vicini, 1998; Rumbaugh and Vicini, 1999; Tovar and Westbrook, 1999; Townsend et al, 2003; Liu et al, 2004). However, the late EPSCs cannot be mimicked simply by increased ambient glutamate after uptake is blocked with TBOA. Together, these results suggest that psychedelic hallucinogens enhance network activity in the rat prefrontal cortex through a phasic increase in glutamate spillover.

\section{Mechanistic Analysis}

Glutamate spillover appears to be critical for triggering late EPSCs or UP states in submerged brain slice of the rat prefrontal cortex; however, it is known that such waves of activity depend on traditional synaptic transmission in a network of neurons (Sutor and Hablitz, 1989; Shu et al, 2003; Hasenstaub et al, 2005). This critical role of network activity complicates analysis of the mechanism underlying the enhancement of late EPSCs or UP states by psychedelic hallucinogens. For example, while late EPSCs received by the recorded neuron depend on stimulation of NR2Bcontaining NMDA receptors, these receptors may be widely distributed within the network. Consistent with previous work in this field (Sutor and Hablitz, 1989; Shu et al, 2003), manipulating NMDA receptor activation in the recorded neuron by changing the holding potential or with MK-801 open channel blockade (data not shown) does not prevent the occurrence of late EPSCs or UP states.

Underlying mechanisms could involve a $5-\mathrm{HT}_{2 \mathrm{~A}}$ receptormediated increase in phasic glutamate release, a reduction in rapid uptake, or potentially an enhancement in the detection of glutamate spillover. Recent work demonstrates that $5-\mathrm{HT}_{2 \mathrm{~A}}$ receptors can enhance the gain on prefrontal pyramidal neurons (Zhang and Arsenault, 2005). However, there is also an emerging body of evidence suggesting that stimulated vesicular release of glutamate from astrocytes can activate extrasynaptic NMDA receptors and enhance neuronal synchrony (Fellin et al, 2004). Interestingly, ultrastructural work has demonstrated the presence of $5-\mathrm{HT}_{2 \mathrm{~A}}$ receptors on glial processes in the medial prefrontal cortex (Miner et al, 2003). Alternatively, blockade of only one subtype of glutamate transporter may result in enhanced phasic glutamate spillover without also raising tonic levels of extrasynaptic glutamate. It is also conceivable that psychedelic hallucinogens enhance network activation by increasing detection of already occurring glutamate spillover.

\section{Physical Arrangement Favors Spillover}

Spines in cortex are also known to have substantially less glial cover ( $\sim 30 \%$ of the spine) than in other brain areas such as the cerebellum ( $\sim 75 \%$ of the spine) (Spacek, 1985), which suggests that it may be an environment conducive to spillover. Physiological variations in glial coverage have been shown to alter glutamate diffusion in the extracellular space (Piet et al, 2004). The ability of psychedelic hallucinogens to enhance either spillover, or detection of spillover, in the prefrontal cortical slice may arise from the density of $5-\mathrm{HT}_{2 \mathrm{~A}}$ receptors on apical dendrites of layer $\mathrm{V}$ neurons (Blue et al, 1988; Cornea-Hebert et al, 1999; Hamada et al, 1998; Jakab and Goldman-Rakic, 1998; Willins et al, 1997; Xu and Pandey, 2000; Miner et al, 2003), together with the arrangement of these apical dendrites in bundles (Gabbott and Bacon, 1996; Skoglund et al, 2004). These structural features may contribute to the ability of psychedelic hallucinogens to enhance spillover or detection of spillover in the medial prefrontal cortex. 


\section{Possible Recruitment of Presynaptic NMDA Receptors}

The ability of NR2B selective antagonists to suppress DOIenhanced late EPSCs supports the involvement of extrasynaptic NMDA receptors. At the low concentrations used, these antagonists are selective for NR2B (Williams, 1993; Fischer et al, 1997). The convergence of their effects helps to rule out the likelihood that their suppression of DOI-elicited late EPSCs was nonspecific. While NR2B receptors are omnipresent in the young rat, by adulthood they are thought to be located mainly at extrasynaptic locations (Stocca and Vicini, 1998; Rumbaugh and Vicini, 1999; Tovar and Westbrook, 1999; Townsend et al, 2003; Liu et al, 2004; but see Charton et al, 1999). Ultrastructural studies show them postsynaptically at the edge of synapses (Fujisawa and Aoki, 2003). However, another potential target of glutamate spillover could be presynaptic NMDA receptors. Recent ultrastructural work has shown the presence of NMDA receptors on axon terminals in the cortex (Conti et al, 1999; Aoki et al, 2003; Fujisawa and Aoki, 2003), cerebellum (Duguid and Smart, 2004), and hippocampus (Janssen et al, 2005).

The presence of NMDA receptors presynaptically on GABAergic terminals raises the question of whether glutamate spillover enhances a late form of GABA transmission as well. While this question is beyond the scope of the current work, there is support for this hypothesis in microdialysis work showing that psychedelic hallucinogens enhance extracellular GABA levels in the prefrontal cortex (Abi-Saab et al, 1999). A balance in glutamatergic and GABAergic excitation, akin to that observed in UP states (Shu et al, 2003; Hasenstaub et al, 2005), would further explain why psychedelic hallucinogens are not convulsants (Rodin and Luby, 1966). While frequent UP states are characteristic of alert waking (Steriade et al, 2001), psychedelic hallucinogens may perturb perception and cognition by pushing such states beyond normal limits.

\section{Caveats}

The use of dextran to increase the viscosity of the extracellular space has been extensively examined. Dextran is an inert macromolecule and is known at the concentration used to reduce diffusion on the order of $25-30 \%$ (Nielsen et al, 2004). On the other hand, the suppression of DOI-enhanced late EPSCs is $\sim 75 \%$ which suggests that the late EPSCs may be mediated by more distant diffusion of glutamate. In this study, we found no significant changes in membrane properties and excitability of neurons in the medial prefrontal cortex in the presence of dextran. Previous work has examined the effects of dextran on the slice and found no significant changes in spine head size, fine branching, or shrinkage (Savtchenko and Rusakov, 2005).

\section{Clinical Significance}

The ability of psychedelic hallucinogens to increase glutamate spillover and excite extrasynaptic NMDA receptors would allow the recruitment of adjacent synapses not directly activated by external stimuli. Such recruitment is consistent with accounts of perturbations in perceptual and cognitive boundaries reported by people who have taken psychedelic hallucinogens. As hyperglutamatergic states may be involved in prodromal stages of schizophrenia (Vollenweider et al, 1997), our work suggests that NR2B antagonists may have potential as novel therapeutic or prophylactic agents in this condition. In contrast to broadspectrum NMDA antagonists, selective antagonists for NMDA receptors containing the NR2B subunit have not been reported to be psychotomimetic in humans (Merchant et al, 1999) and may enhance some aspects of cognitive performance in rats (Higgins et al, 2005).

\section{ACKNOWLEDGEMENTS}

We thank Ms Nancy Margiotta for her excellent technical assistance. This work was supported by a Kevin Hines NARSAD Young Investigator Award (EKL) and NIMH 17871 (GKA).

\section{REFERENCES}

Abi-Saab WM, Bubser M, Roth RH, Deutch AY (1999). 5- $\mathrm{HT}_{2}$ receptor regulation of extracellular GABA levels in the prefrontal cortex. Neuropsychopharmacology 20: 92-96.

Aghajanian GK, Marek GJ (1999). Serotonin, via 5- $\mathrm{HT}_{2 \mathrm{~A}}$ receptors, increases EPSCs in layer $\mathrm{V}$ pyramidal cells of prefrontal cortex by an asynchronous mode of glutamate release. Brain Res 825: $161-171$.

Aoki C, Fujisawa S, Mahadomrongkul V, Shah PJ, Nader K, Erisir A (2003). NMDA receptor blockade in intact adult cortex increases trafficking of NR2A subunits into spines, postsynaptic densities, and axon terminals. Brain Res 963: 139-149.

Barbour B, Hausser M (1997). Intersynaptic diffusion of neurotransmitter. Trends Neurosci 20: 377-384.

Beique JC, Campbell B, Perring P, Hamblin MW, Walker P, Mladenovic L et al (2004). Serotonergic regulation of membrane potential in developing rat prefrontal cortex: coordinated expression of 5-hydroxytryptamine $(5-\mathrm{HT})_{1 \mathrm{~A}}, 5-\mathrm{HT}_{2 \mathrm{~A}}$, and 5- $\mathrm{HT}_{7}$ receptors. J Neurosci 24: 4807-4817.

Blue ME, Yagaloff KA, Mamounas LA, Hartig PR, Molliver ME (1988). Correspondence between $5-\mathrm{HT}_{2}$ receptors and serotonergic axons in rat neocortex. Brain Res 453: 315-328.

Charton JP, Herkert M, Becker CM, Schroder H (1999). Cellular and subcellular localization of the $2 \mathrm{~B}$-subunit of the NMDA receptor in the adult rat telencephalon. Brain Res 816: 609-617.

Conti F, Barbaresi P, Melone M, Ducati A (1999). Neuronal and glial localization of NR1 and NR2A/B subunits of the NMDA receptor in the human cerebral cortex. Cereb Cortex 9: 110-120.

Cornea-Hebert V, Riad M, Wu C, Singh SK, Descarries L (1999). Cellular and subcellular distribution of the serotonin $5-\mathrm{HT}_{2 \mathrm{~A}}$ receptor in the central nervous system of adult rat. J Comp Neurol 409: 187-209.

Diamond JS (2001). Neuronal glutamate transporters limit activation of NMDA receptors by neurotransmitter spillover on CA1 pyramidal cells. J Neurosci 21: 8328-8338.

Duguid IC, Smart TG (2004). Retrograde activation of presynaptic NMDA receptors enhances GABA release at cerebellar interneuron-Purkinje cell synapses. Nat Neurosci 7: 525-533.

Fellin T, Pascual O, Gobbo S, Pozzan T, Haydon PG, Carmignoto G (2004). Neuronal synchrony mediated by astrocytic glutamate through activation of extrasynaptic NMDA receptors. Neuron 43: 729-743. 
Fischer G, Mutel V, Trube G, Malherbe P, Kew JN, Mohacsi E et al (1997). Ro 25-6981, a highly potent and selective blocker of $\mathrm{N}$-methyl-D-aspartate receptors containing the NR2B subunit. Characterization in vitro. J Pharmacol Exp Ther 283: 1285-1292.

Fujisawa S, Aoki C (2003). In vivo blockade of $N$-methyl-Daspartate receptors induces rapid trafficking of NR2B subunits away from synapses and out of spines and terminals in adult cortex. Neuroscience 121: 51-63.

Gabbott PL, Bacon SJ (1996). The organisation of dendritic bundles in the prelimbic cortex (area 32) of the rat. Brain Res 730: $75-86$.

Gouzoulis-Mayfrank E, Schreckenberger M, Sabri O, Arning C, Thelen B, Spitzer M et al (1999). Neurometabolic effects of psilocybin, 3,4-methylenedioxyethylamphetamine (MDE) and d-methamphetamine in healthy volunteers. A double-blind, placebo-controlled PET study with [18F]FDG. Neuropsychopharmacology 20: 565-581.

Hamada S, Senzaki K, Hamaguchi-Hamada K, Tabuchi K, Yamamoto $\mathrm{H}$, Yamamoto $\mathrm{T}$ et al (1998). Localization of $5-\mathrm{HT}_{2 \mathrm{~A}}$ receptor in rat cerebral cortex and olfactory system revealed by immunohistochemistry using two antibodies raised in rabbit and chicken. Mol Brain Res 54: 199-211.

Hasenstaub A, Shu Y, Haider B, Kraushaar U, Duque A, McCormick DA (2005). Inhibitory postsynaptic potentials carry synchronized frequency information in active cortical networks. Neuron 47: 423-435.

Higgins GA, Ballard TM, Enderlin M, Haman M, Kemp JA (2005). Evidence for improved performance in cognitive tasks following selective NR2B NMDA receptor antagonist pre-treatment in the rat. Psychopharmacology (Berl) 179: 85-98.

Huang YH, Bergles DE (2004). Glutamate transporters bring competition to the synapse. Curr Opin Neurobiol 14: 346-352.

Jakab RL, Goldman-Rakic PS (1998). 5-Hydroxytryptamine 2 A serotonin receptors in the primate cerebral cortex: possible site of action of hallucinogenic and antipsychotic drugs in pyramidal cell apical dendrites. Proc Natl Acad Sci 95: 735-740.

Janssen WG, Vissavajjhala P, Andrews G, Moran T, Hof PR, Morrison JH (2005). Cellular and synaptic distribution of NR2A and NR2B in macaque monkey and rat hippocampus as visualized with subunit-specific monoclonal antibodies. Exp Neurol 191(Suppl 1): S28-S44.

Kalandadze A, Wu Y, Robinson MB (2002). Protein kinase C activation decreases cell surface expression of the GLT-1 subtype of glutamate transporter. Requirement of a carboxyl-terminal domain and partial dependence on serine 486. J Biol Chem 277: 45741-45750.

Kullmann DM, Erdemli G, Asztely F (1996). LTP of AMPA and NMDA receptor-mediated signals: evidence for presynaptic expression and extrasynaptic glutamate spill-over. Neuron 17: 461-474.

Lambe EK, Aghajanian GK (2003). Hypocretin (orexin) induces calcium transients in single spines postsynaptic to identified thalamocortical boutons in prefrontal slice. Neuron 40: 139-150.

Liu XB, Murray KD, Jones EG (2004). Switching of NMDA receptor $2 \mathrm{~A}$ and $2 \mathrm{~B}$ subunits at thalamic and cortical synapses during early postnatal development. J Neurosci 24 : 8885-8895.

Lozovaya NA, Grebenyuk SE, Tsintsadze T, Feng B, Monaghan DT, Krishtal OA (2004). Extrasynaptic NR2B and NR2D subunits of NMDA receptors shape 'superslow' afterburst EPSC in rat hippocampus. J Physiol 558: 451-463.

Marek GJ, Aghajanian GK (1999). 5- $\mathrm{HT}_{2 \mathrm{~A}}$ receptor or alpha1adrenoceptor activation induces excitatory postsynaptic currents in layer V pyramidal cells of the medial prefrontal cortex. Eur J Pharmacol 367: 197-206.

Melendez RI, Vuthiganon J, Kalivas PW (2005). Regulation of extracellular glutamate in the prefrontal cortex: focus on the cystine glutamate exchanger and group I metabotropic glutamate receptors. J Pharmacol Exp Ther 314: 139-147.
Merchant RE, Bullock MR, Carmack CA, Shah AK, Wilner KD, Ko G et al (1999). A double-blind, placebo-controlled study of the safety, tolerability and pharmacokinetics of CP-101,606 in patients with a mild or moderate traumatic brain injury. Ann NY Acad Sci 890: 42-50.

Min MY, Rusakov DA, Kullmann DM (1998). Activation of AMPA, kainate, and metabotropic receptors at hippocampal mossy fiber synapses: role of glutamate diffusion. Neuron 21: 561-570.

Miner LA, Backstrom JR, Sanders-Bush E, Sesack SR (2003). Ultrastructural localization of serotonin $2 \mathrm{~A}$ receptors in the middle layers of the rat prelimbic prefrontal cortex. Neuroscience 116: 107-117.

Muschamp JW, Regina MJ, Hull EM, Winter JC, Rabin RA (2004). Lysergic acid diethylamide and [-]-2,5-dimethoxy-4-methylamphetamine increase extracellular glutamate in rat prefrontal cortex. Brain Res 1023: 134-140.

Nichols DE (2004). Hallucinogens. Pharmacol Ther 101: 131-181. Nielsen TA, DiGregorio DA, Silver RA (2004). Modulation of glutamate mobility reveals the mechanism underlying slowrising AMPAR EPSCs and the diffusion coefficient in the synaptic cleft. Neuron 42: 757-771.

Perrais D, Ropert N (2000). Altering the concentration of GABA in the synaptic cleft potentiates miniature IPSCs in rat occipital cortex. Eur J Neurosci 12: 400-404.

Piet R, Vargova L, Sykova E, Poulain DA, Oliet SH (2004). Physiological contribution of the astrocytic environment of neurons to intersynaptic crosstalk. Proc Natl Acad Sci USA 101: 2151-2155.

Rodin E, Luby E (1966). Effects of LSD-25 on the EEG and photic evoked responses. Arch Gen Psychiatry 14: 435-441.

Rumbaugh G, Vicini S (1999). Distinct synaptic and extrasynaptic NMDA receptors in developing cerebellar granule neurons. J Neurosci 19: 10603-10610.

Rusakov DA, Kullmann DM (1998). Extrasynaptic glutamate diffusion in the hippocampus: ultrastructural constraints, uptake, and receptor activation. J Neurosci 18: 3158-3170.

Savtchenko LP, Rusakov DA (2005). Extracellular diffusivity determines contribution of high-versus low-affinity receptors to neural signaling. Neuroimage 25: 101-111.

Scimemi A, Fine A, Kullmann DM, Rusakov DA (2004). NR2Bcontaining receptors mediate cross talk among hippocampal synapses. J Neurosci 24: 4767-4777.

Scruggs JL, Schmidt D, Deutch AY (2003). The hallucinogen 1[2,5-dimethoxy-4-iodophenyl]-2-aminopropane (DOI) increases cortical extracellular glutamate levels in rats. Neurosci Lett 346: 137-140.

Shu Y, Hasenstaub A, McCormick DA (2003). Turning on and off recurrent balanced cortical activity. Nature 423: 288-293.

Skoglund TS, Pascher R, Berthold CH (2004). Aspects of the organization of neurons and dendritic bundles in primary somatosensory cortex of the rat. Neurosci Res 50: 189-198.

Spacek J (1985). Three-dimensional analysis of dendritic spines. III. Glial sheath. Anat Embryol (Berl) 171: 245-252.

Steriade M, Timofeev I, Grenier F (2001). Natural waking and sleep states: a view from inside neocortical neurons. J Neurophysiol 85: 1969-1985.

Stocca G, Vicini S (1998). Increased contribution of NR2A subunit to synaptic NMDA receptors in developing rat cortical neurons. J Physiol 507(Part 1): 13-24.

Stutzmann GE, Marek GJ, Aghajanian GK (2001). Adenosine preferentially suppresses serotonin2A receptor-enhanced excitatory postsynaptic currents in layer $\mathrm{V}$ neurons of the rat medial prefrontal cortex. Neuroscience 105: 55-69.

Sutor B, Hablitz JJ (1989). EPSPs in rat neocortical neurons in vitro. II. Involvement of NMDA receptors in the generation of EPSPs. J Neurophysiol 61: 621-634. 
Tovar KR, Westbrook GL (1999). The incorporation of NMDA receptors with a distinct subunit composition at nascent hippocampal synapses in vitro. J Neurosci 19: 4180-4188.

Townsend M, Yoshii A, Mishina M, Constantine-Paton M (2003). Developmental loss of miniature $\mathrm{N}$-methyl-D-aspartate receptor currents in NR2A knockout mice. Proc Natl Acad Sci USA 100: 1340-1345.

Vollenweider FX, Leenders KL, Scharfetter C, Maguire P, Stadelmann O, Angst J (1997). Positron emission tomography and fluorodeoxyglucose studies of metabolic hyperfrontality and psychopathology in the psilocybin model of psychosis. Neuropsychopharmacology 16: 357-372.

Williams K (1993). Ifenprodil discriminates subtypes of the $\mathrm{N}$-methyl-D-aspartate receptor: selectivity and mechanisms at recombinant heteromeric receptors. Mol Pharmacol 44: 851-859.

Willins DL, Deutch AY, Roth BL (1997). Serotonin 5- $\mathrm{HT}_{2 \mathrm{~A}}$ receptors are expressed on pyramidal cells and interneurons in the rat cortex. Synapse 27: 79-82.

$\mathrm{Xu} \mathrm{T}$, Pandey SC (2000). Cellular localization of serotonin ${ }_{2 \mathrm{~A}}$ $\left(5-\mathrm{HT}_{2 \mathrm{~A}}\right)$ receptors in the rat brain. Brain Res Bull 51: 499-505.

Zhang ZW (2003). Serotonin induces tonic firing in layer V pyramidal neurons of rat prefrontal cortex during postnatal development. J Neurosci 23: 3373-3384.

Zhang ZW, Arsenault D (2005). Gain modulation by serotonin in pyramidal neurones of the rat prefrontal cortex. J Physiol 566: 379-394. 